\title{
Enhanced tolerance to oxidative stress in transgenic tobacco plants expressing three antioxidant enzymes in chloroplasts
}

\author{
Young-Pyo Lee $\cdot$ Sun-Hyung Kim · Jae-Wook Bang • \\ Haeng-Soon Lee · Sang-Soo Kwak • Suk-Yoon Kwon
}

Received: 28 July 2006 / Revised: 11 September 2006 / Accepted: 17 September 2006 / Published online: 1 February 2007

(C) Springer-Verlag 2006

\begin{abstract}
The effect of simultaneous expression of genes encoding three antioxidant enzymes, copper zinc superoxide dismutase (CuZnSOD, EC 1.15.1.1), ascorbate peroxidase (APX, EC 1.11.1.11), and dehydroascorbate (DHA) reductase (DHAR, EC 1.8.5.1), in the chloroplasts of tobacco plants was investigated under oxidative stress conditions. In previous studies, transgenic tobacco plants expressing both CuZnSOD and APX in chloroplast (CA plants), or DHAR in chloroplast showed enhanced tolerance to oxidative stresses, such as paraquat and salt. In this study, in order to develop transgenic plants that were more resistant to oxidative stress, we introduced the gene encoding DHAR into CA transgenic plants. Mature leaves of transgenic plants expressing all three antioxidant genes (CAD plants) had approximately 1.6-2.1 times higher DHAR activity, and higher ratios of reduced ascorbate (AsA) to DHA, and oxidized glutathione (GSSG) to reduced glutathione (GSH) compared to CA plants. CAD plants were more resistant to paraquat-induced stress, exhibiting only $18.1 \%$ reduction in membrane damage relative to CA plants. In addition, seedlings of CAD plants had enhanced tolerance to $\mathrm{NaCI}(100 \mathrm{mM})$ compared to CA plants. These results indicate that the simultaneous expression of multiple antioxidant enzymes, such as CuZnSOD, APX, and
\end{abstract}

Communicated by J. R. Liu

Y.-P. Lee · S.-H. Kim · H.-S. Lee · S.-S. Kwak · S.-Y. Kwon ( ()

Environmental Biotechnology Research Center, KRIBB,

Eoeun-dong 52, Yuseong-gu, Daejeon, 305-806 Korea

e-mail: sykwon@kribb.re.kr

Y.-P. Lee - J.-W. Bang

Department of Biology, Chungnam National University,

Daejeon, 305-764 Korea

S.-H. Kim

Department of Environmental Horticulture, University of Seoul, Seoul, 130-743 Korea
DHAR, in chloroplasts is more effective than single or double expression for developing transgenic plants with enhanced tolerance to multiple environmental stresses.

Keywords Ascorbate - Ascorbate peroxidase ·

Chloroplast · Dehydroascorbate reductase - Glutathione ·

Methyl viologen · Oxidative stress $\cdot$ Superoxide dismutase

\section{Introduction}

Oxygen is essential for the existence of aerobic life, but toxic reactive oxygen species (ROS), including the superoxide anion radical, the hydroxyl radical, and hydrogen peroxide, tend to increase in plants exposed to stressful conditions. Injuries associated with ROS, collectively referred to as oxidative stresses, are among the most profound damaging factors in plants. Therefore, plants have developed a number of antioxidant defense mechanisms to protect themselves against ROS. These mechanisms employ such factors as antioxidant enzymes, including SOD, peroxidase (POD), and catalase (CAT), as well as low molecular weight antioxidants, including ascorbic acid, GSH, and phenolic compounds (Noctor and Foyer 1998; Asada 1999).

Chloroplasts are the primary source of ROS, as electrons escaping from the photosynthetic electron transfer system interact with molecular oxygen, thereby resulting in the generation of superoxide anion radicals (Foyer et al. 1994). Under conditions of environmental stress, including high temperatures, low temperatures, salinity, and drought, ROS levels are increased in plant cells, a process which ultimately hinders the productivity of plants. The water-water cycle (Asada 1999) operates in chloroplasts, rapidly removing ROS at their site of generation, prior to their interaction with target molecules. In this cycle, antioxidant enzymes, including SOD, APX, DHAR, and glutathione reductase 
(GR), are involved in the scavenging of ROS and the regeneration of oxidized ascorbate and glutathione.

Experiments using transgenic plants expressing foreign genes for antioxidant enzymes have shown that a variety of genes are used in several plant species (McKersie et al. 1993, 2000; Sen Gupta et al. 1993; Allen et al. 1997; Payton et al. 1997; Chen et al. 2003). In previous studies, we found that transgenic tobacco plants expressing both CuZnSOD and APX in chloroplasts (referred to as CA plants) showed evidence of elevated tolerance to oxidative stresses induced by methyl viologen (MV), a ROS-generating herbicide (Kwon et al. 2002). Transgenic plants expressing human DHAR in their chloroplasts had high AsA levels and showed increased tolerance to both MV-induced oxidative stress and salt stress (Kwon et al. 2003). Thus, the development of transgenic plants with optimized tolerance to environmental stresses may require the expression of a variety of antioxidant enzymes, such as CuZnSOD, APX, and DHAR. In this report, we describe the development of transgenic tobacco plants that simultaneously express CuZnSOD, APX, and DHAR in their chloroplasts. Simultaneous expression of these antioxidant enzymes confers increased protection against MVinduced damage and salt-induced damage, indicating that the rational manipulation of antioxidant mechanisms in chloroplasts may prove important with regard to the protection of plant cells against multiple environmental stresses.

\section{Materials and methods}

Plant materials and transformation

Transgenic tobacco (Nicotiana tabacum cv. Xanthi) plants expressing CuZnSOD, APX, and DHAR were generated by the transformation of transgenic CA plants (Kwon et al. 2002) with a chloroplast-targeted DHAR gene (Kwon et al. 2001), using hygromycin as a selection marker. The fully grown transgenic plants ( $\mathrm{T}_{0}$ generation) were then selfpollinated using glassine envelopes, resulting in the production of $\mathrm{T}_{1}$ seeds. $\mathrm{T}_{2}$ plants selected with hygromycin (25 mg/L) on MS (Murashige and Skoog 1962) agar medium were allowed to grow in a growth room at $25^{\circ} \mathrm{C}$, with a 16 $\mathrm{h}$ photoperiod. Three to four-week-old seedlings were then transplanted into pots, and grown in greenhouses (16 h days, $30^{\circ} \mathrm{C}$ day and $22^{\circ} \mathrm{C}$ night) with daily watering. Plants were allowed to grow in $10 \mathrm{~cm}$-diameter pots containing commercial mineral-mixed soil. Eight-week-old plants at the fiveleaf stage were utilized for ion leakage analyses.

Vector construction

A binary vector containing the hygromycin resistance gene (pCAMBIA1300) was used for transformation of CA plants, which harbor genes conferring resistance to kanamycin and basta (Kwon et al. 2002). A chimeric DHAR gene construct (Kwon et al. 2001) was digested with PstI and ligated into the same site of pCAMBIA1300. Agrobacterium tumefaciens EHA105 was employed for transformation of the tobacco plants.

Biochemical analysis

The activity of DHAR was analyzed by the method of Nakano and Asada (1981). Briefly, to determine enzyme activity, the formation of AsA from DHA was monitored at $265 \mathrm{~nm}$ in $50 \mathrm{mM}$ phosphate buffer ( $\mathrm{pH}$ 7.0) containing $0.1 \mathrm{mM}$ EDTA, $2.5 \mathrm{mM}$ GSH and crude extract. In-gel detection of SOD isoenzymes was done via nitroblue tetrazolium (NBT) reduction by photochemically generated superoxide radicals, as originally described by Beauchamp and Fridovich (1971). The expression of APX in transgenic plants was determined by isoenzyme analysis, according to the methods of Mittler and Zilinskas (1994). Endogenous ascorbate was extracted and analyzed according to the method developed by Graham and Annette (1992), with slight modifications (Ahn et al. 1999). Aminex HPX-87H ion exclusion chromatography (BioRad, USA, http://www.bio-rad.com) was used to quantify ascorbate using HPLC analysis. GSH content was measured according to the method of Griffith (1980), using GR and 4-vinylpyridine.

Reverse transcriptase-polymerase chain reaction (RT-PCR)

For analysis of transcriptional levels of the introduced DHAR gene, the fourth to fifth leaves from the top of NT, CA, and CAD plants were sampled. Total RNA was extracted from the leaves using the cetyltrimethylammonium bromide (CTAB) method (Kim and Hamada 2005). Total RNA was treated extensively with RNase-free DNase I to remove any contaminating genomic DNA. First-strand cDNA was synthesized from $1 \mu \mathrm{g}$ of total RNA using MMLV Reverse Transcriptase (Clontech, USA, http://www.clontech.com/clontech) in a $20 \mu \mathrm{L}$ reaction volume, then $1 \mu \mathrm{L}$ of the reaction mixture was subjected to PCR analysis in a $50 \mu \mathrm{L}$ reaction volume. Primers specific for DHAR (5'-TCC GAG TCG ACA GCA TGA GGT TCT- $3^{\prime}$ and 5'-CTG GAT CCT CAG AGC CCA TAA T- $\left.3^{\prime}\right)$ and actin (5'-TGG ACT CTG GTG ATG GTG TC-3' and 5'-CCT CCA ATC CAA ACA CTG TA- $3^{\prime}$ ), were used, and the reaction was carried out for 30 cycles under the following conditions for each cycle: $94^{\circ} \mathrm{C}$ for $0.5 \mathrm{~min}, 53^{\circ} \mathrm{C}$ for $0.5 \mathrm{~min}$, and $72^{\circ} \mathrm{C}$ for $1 \mathrm{~min}$. This was followed by a final cycle at $72^{\circ} \mathrm{C}$ for 5 min to allow completion of polymerization. Actin mRNA served as an internal control. 
MV treatment and ion leakage analysis

MV damage was analyzed using leaf discs, as described by Yun et al. (2000), with slight modifications. Leaf discs (16 mm diameter) from the third leaves of six different plants were transferred to $5.0-\mathrm{cm}$ Petri dishes, each containing $5 \mathrm{~mL}$ of MV solution at various concentrations $(0,2,5 \mu \mathrm{mol} / \mathrm{L})$. Eight leaf discs were placed in each Petri dish, and then incubated for $12 \mathrm{~h}$ at $25^{\circ} \mathrm{C}$ in darkness to allow for $\mathrm{MV}$ to diffuse into the leaves. After pre-incubation, the leaf discs were illuminated $\left(500 \mu \mathrm{mol} / \mathrm{m}^{2} / \mathrm{s}\right)$ until use. The conductivity of the decanted MV solution was determined with an ion conductivity meter (lstek Co., Seoul, Korea, model 455C, http://www.istek.co.kr). The solution was recovered from the conductivity meter cell and autoclaved, with the damaged leaf discs, for $15 \mathrm{~min}$ at $121^{\circ} \mathrm{C}$, in order to release all of the solutes. The conductivity of the solution was then again determined, and the percent electrolyte leakage attributable to MV treatment was determined by dividing the conductivity value of the sample before autoclaving by the conductivity of the sample after autoclaving (100\% electrolyte leakage).

Salt-stress treatment and seedling growth

Transgenic $\mathrm{T}_{2}$ seeds were germinated on agar medium containing hygromycin $(25 \mathrm{mg} / \mathrm{L})$. Six-day-old seedlings were transplanted into test tubes $(3 \mathrm{~cm} \times 15 \mathrm{~cm})$, each containing $25 \mathrm{~mL}$ of basal MS medium, and then incubated under $125 \mu \mathrm{mol} / \mathrm{m}^{2} / \mathrm{s}$ of light at $25^{\circ} \mathrm{C}$, with a $16 \mathrm{~h}$ photoperiod. For salt treatment, seedlings were allowed to grow in basal MS medium containing 0 or $100 \mathrm{mM} \mathrm{NaCl}$ for 40 days. The fresh and dry weights of the stress-treated plants were measured, as were the lengths of the shoots and roots.

Photosynthetic efficiency

The recovery of photosynthetic activity after MV-treatment was estimated by chlorophyll fluorescence determination of photochemical yield $\left(F_{\mathrm{v}} / F_{\mathrm{m}}\right)$, which also represented the maximal yield of the photochemical reaction in photosystem II, using a portable chlorophyll fluorescence meter (Handy PEA, Hansatech, England, http://www.hansatechinstruments.com/). After $30 \mathrm{~min}$ of adaptation to darkness, measurements were conducted at room temperature $\left(25^{\circ} \mathrm{C}\right)$ using saturating light flashes $\left(2000 \mu \mathrm{mol} / \mathrm{m}^{2} / \mathrm{s}\right)$.

\section{Results}

Transgenic plants expressing CuZnSOD, APX, and DHAR in chloroplasts

Five independent transgenic tobacco plants expressing CuZnSOD, APX, and DHAR were generated by the trans- formation of CA plants with the human DHAR gene. There were no apparent differences in the growth characteristics between the CAD transgenic and NT tobacco plants. Integration of the transgene encoding DHAR was confirmed by PCR and Southern blot analysis, using specific primers and DHAR gene-specific probes (data not shown). DHAR activity (units/g fresh wt) in fully developed leaves of five different transgenic plant lines was 1.4-1.6 times higher than that in NT and CA plants. The CAD2 plant, which had the highest level of DHAR activity among the transgenic lines, was used for further analysis. Fully expanded leaves of the CAD2 plant exhibited approximately 1.6 times higher DHAR activity than NT or CA plants (Fig. 1A). In the CAD2 plant, intense bands corresponding to the SOD and APX isoenzymes were detected in native gel analysis, similar to that seen in CA plants (Fig. 2). These results indicated that the three antioxidant genes were properly integrated into the CAD2 plants. The level of DHAR expression in all five plant lines was analyzed by RT-PCR, and we found no significant differences among them (Fig. 3).

Biochemical characterization of CAD plants

In addition to enzyme activity, the levels of reduced and oxidized ascorbate and glutathione were measured in the fully expanded leaves of NT, CA, and CAD plants (Fig. $1 \mathrm{~B}$ and $\mathrm{C})$. As expected, the level of AsA in CAD plants $(63.3 \mu \mathrm{g} / \mathrm{g}$ fresh wt) was approximately 1.5 and 1.2 times higher than in NT and CA plants, respectively. However, the levels of DHA in the CAD plants was reduced by 35.0 and $16.0 \%$, relative to the levels measured in NT and CA plants, respectively (Fig. 1B). As a result, the AsA:DHA ratio in CAD plants was increased by 2.2-fold and 1.6-fold over that of NT and CA plants, respectively, although the total ascorbate content did not differ significantly among the genotypes. CAD plants also had an altered ratio of reduced to oxidized glutathione, although total glutathione content was similar in the leaves of NT, CA, and CAD plants (Fig. 1C). GSH levels (138.24 $\mu \mathrm{g} / \mathrm{g}$ fresh wt) in the CAD plants were significantly reduced compared to NT and CA plants, whereas the levels of GSSG were increased. Therefore, the ratio of GSSG to GSH in CAD plants was 3.4 and 2.1 times higher than that in NT and CA plants, respectively.

Protection of membrane damage in transgenic plants

To evaluate oxidative stress tolerance in CAD plants, leaf discs were treated with MV, a superoxide-generating herbicide. Severe necrosis was observed in the leaf discs of NT and CA plants treated with MV (Fig. 4A), while partial necrosis was observed at the boundaries of the leaf discs of the CAD plants. As a result, the conductivity of the MV solution containing the leaf discs from CAD plants was 

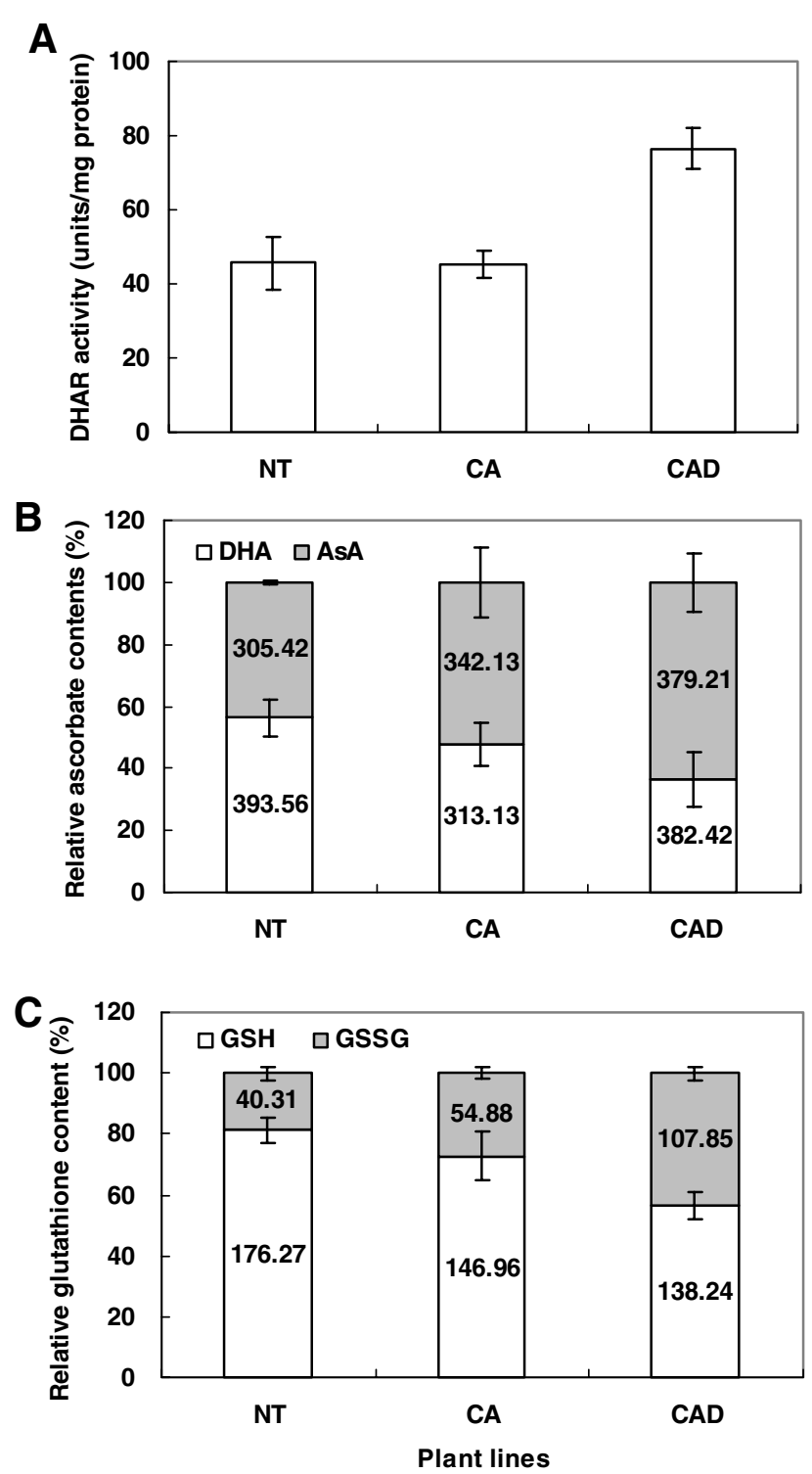

Fig. 1 Biochemical characterization of $\mathrm{CA}$ and $\mathrm{CAD}$ transgenic tobacco plants and NT plants. CA plants express both CuZnSOD and APX in chloroplasts, whereas CAD plants simultaneously express $\mathrm{CuZn}$ SOD, APX, and DHAR in chloroplasts. A DHAR activity in transgenic and NT plants. B Ascorbate contents in transgenic and NT plants. AsA and DHA indicate reduced and oxidized ascorbate, respectively. C Glutathione content in transgenic and NT plants. GSH and GSSG indicate reduced and oxidized glutathione, respectively. Data represents the means \pm standard deviation (SD) of three replicates

lower than that of NT and CA plants. When leaf discs were subjected to $5 \mu \mathrm{M} \mathrm{MV}, 48 \mathrm{~h}$ after treatment, CAD plants showed a reduction in membrane damage of approximately 27.9 and $18.1 \%$ compared to NT and CA plants, respectively (Fig. 4B). This result indicated that CA plants were tolerant to an extent intermediate with regard to that of the NT and CAD plants.

During MV treatment, the photosynthetic efficiency $\left(F_{\mathrm{v}} / F_{\mathrm{m}}\right)$ of the leaf discs was evaluated, in order to deter-

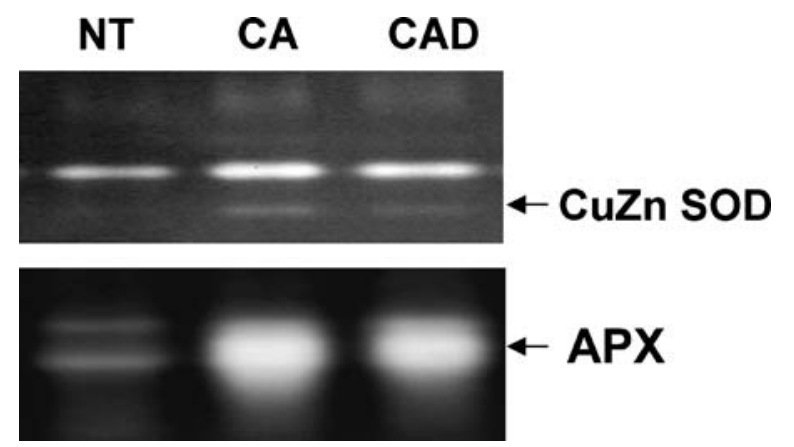

Fig. 2 Native gel analysis of SOD and APX in CA and CAD transgenic tobacco plants and NT plants. Presence of CuZnSOD and APX isoenzymes in the leaves of the transgenic plants is indicated by arrows. Each lane was loaded with $30 \mu \mathrm{g}$ of total protein

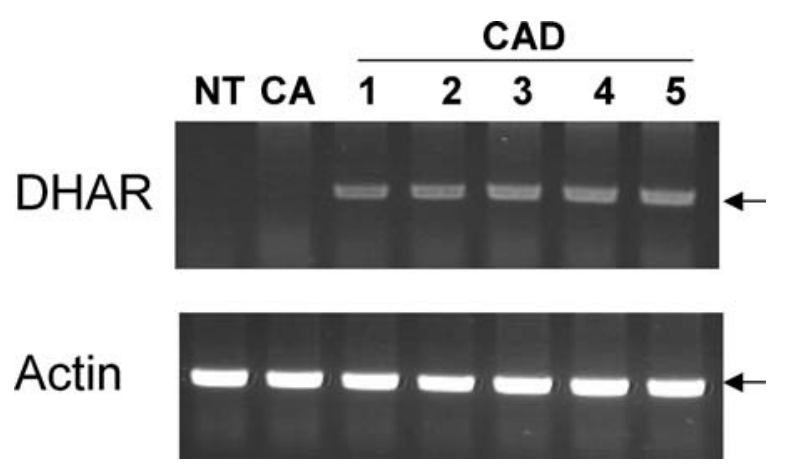

Fig. 3 RT-PCR analysis of the expression of introduced DHAR gene in leaves from NT, CA and CAD tobacco plants. Total RNA was extracted from leaves, and first-strand cDNA synthesis and PCR were performed as outlined in the Materials and Methods section. Actin was used as a control for equal loading. Reaction products $(10 \mu \mathrm{L})$ were analyzed by gel electrophoresis. NT: non-transgenic potato plants; CA: CA plants; $1-5$ : CAD transgenic plants

mine the degree of damage induced by MV treatment on the photosynthetic apparatus. No significant differences in the photosynthetic efficiency in leaf discs from the three plant lines were noted in the absence of MV treatment. When the leaf discs were exposed to MV, only minimal loss of chlorophyll fluorescence was observed in the CAD plants, while photosynthetic efficiency was reduced significantly in the NT and CA plants. When the leaf discs were exposed to $5 \mu \mathrm{M} \mathrm{MV}$, the leaf discs from the CAD plants showed a lower chlorophyll fluorescence loss than NT and CA plants, by 1.42 -fold and 1.5 -fold, respectively, $48 \mathrm{~h}$ after treatment (Fig. 4C).

Effect of $\mathrm{NaCI}$ on seedling growth

In order to determine the effect of $\mathrm{NaCl}$ on plant growth, NT and transgenic plants were grown in test tubes containing MS basal medium supplemented with $100 \mathrm{mM} \mathrm{NaCl}$ for 50 days, and the growth of the plants was compared to the growth of plants grown in MS medium in the absence of $\mathrm{NaCl}$ (Fig. 5). CAD plants showed an enhanced 

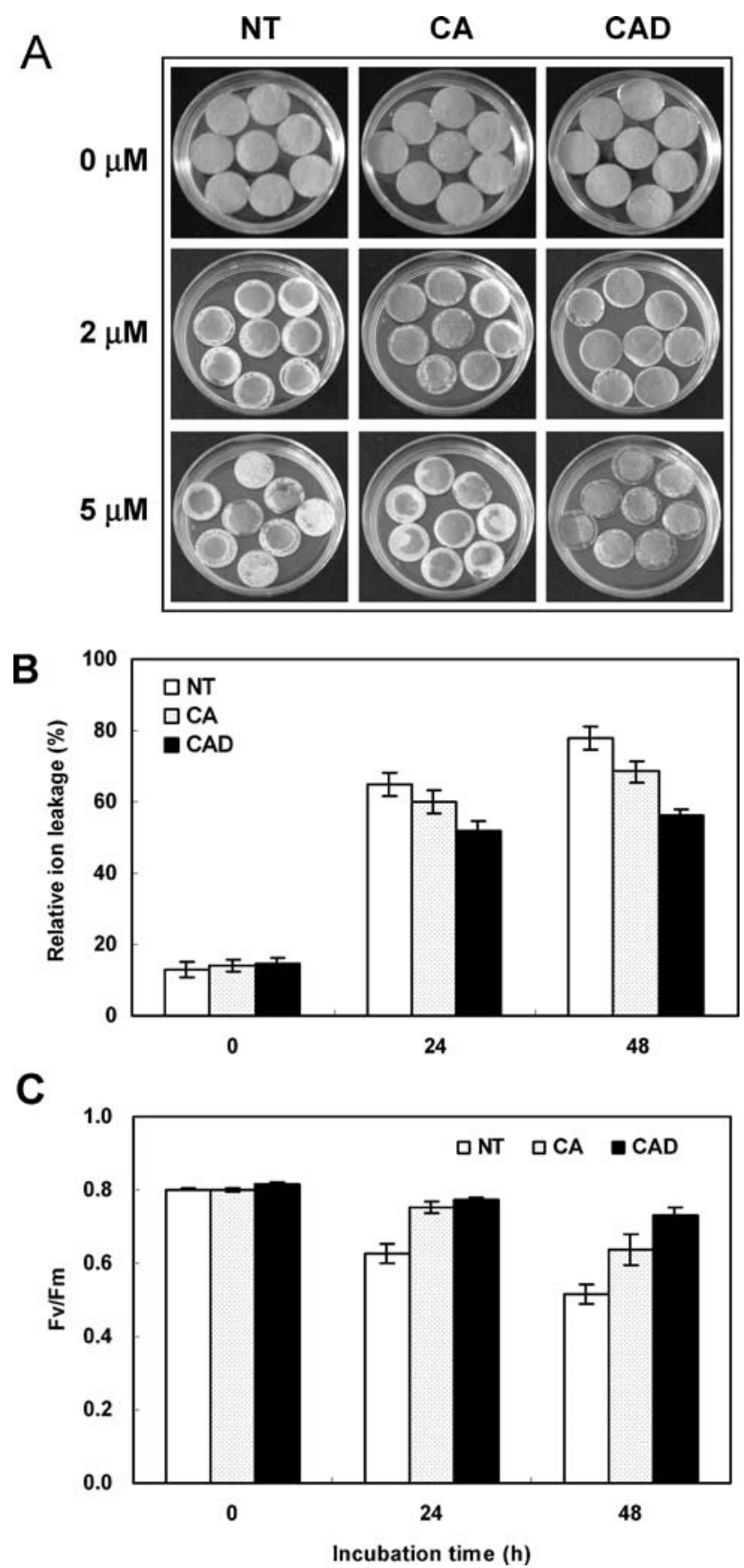

Fig. 4 Analysis of cellular damage in the MV-treated leaf discs from $\mathrm{CA}$ and CAD transgenic tobacco plants NT plants $48 \mathrm{~h}$ after treatment. A Photographs showing the damage to the leaf discs of transgenic $\mathrm{CA}, \mathrm{CAD}$, and NT plants treated with 2 or $5 \mu \mathrm{M}$ MV. B Relative electrolyte leakage from the leaf discs of the transgenic CA, CAD, and NT plants treated with $5 \mu \mathrm{M}$ MV. Data represents the means \pm SD of three replicates. C Photosynthetic efficiency measured by chlorophyll fluorescence, expressed as the $F_{\mathrm{v}} / F_{\mathrm{m}}$ ratio, after the treatment of leaf discs from transgenic CA, CAD and NT plants with $5 \mu \mathrm{M}$ MV. Data represents the means $\pm \mathrm{SD}$ of 10 independent measurements

A
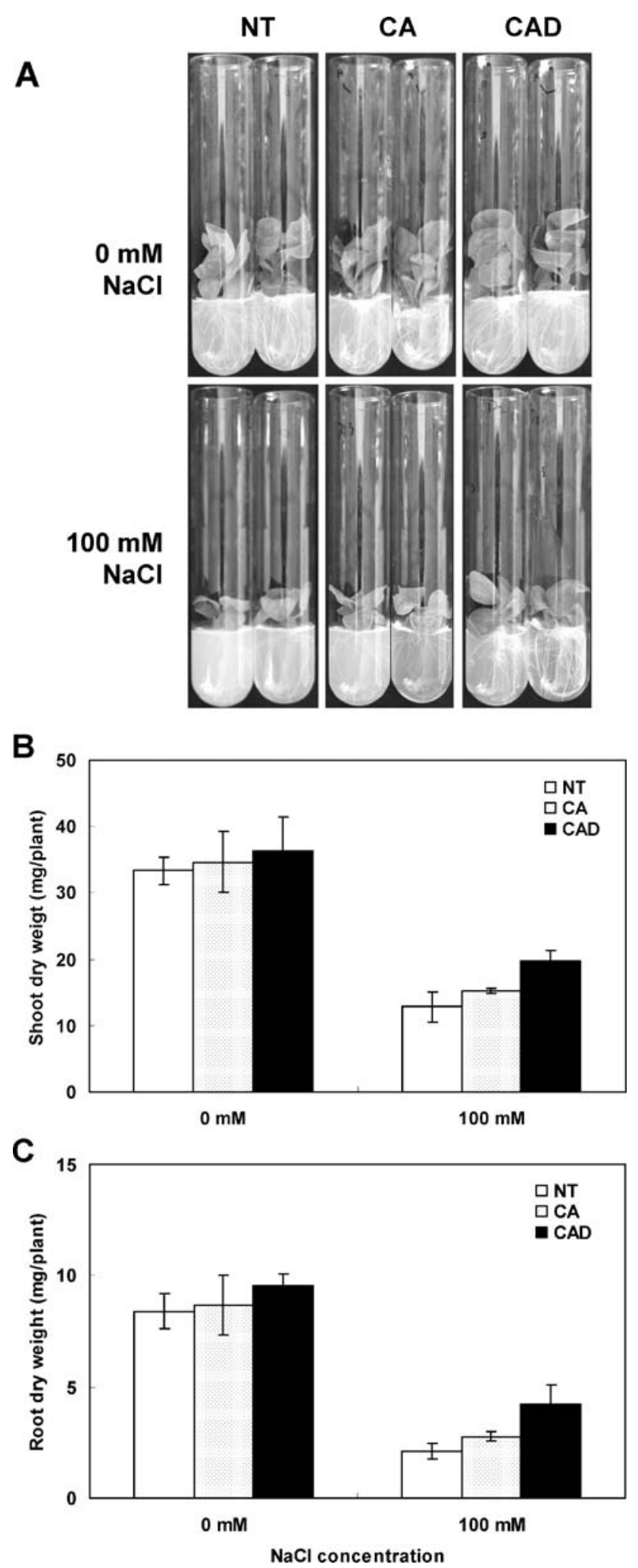

Fig. 5 Effect of salt stress on the growth of seedlings of CA and CAD transgenic tobacco plants and NT plants. A Photographs of plants treated with 0 or $100 \mathrm{mM} \mathrm{NaCl} 40$ days after treatment. B Shoot dry weight (mg/plant). C Root dry weight (mg/plant). Data represents the means $\pm \mathrm{SD}$ of three replicates 
degree of tolerance to NaCl-mediated stress, as compared to NT and CA plants. The administration of $100 \mathrm{mM} \mathrm{NaCl}$ induced significant growth retardation in all tobacco plant lines (Fig. 5A). However, the growth retardation of CAD plants induced by $\mathrm{NaCl}$ treatment was less profound than that of NT and CA plants. The shoot dry weights of the CAD plants were 35.0 and $22.3 \%$ higher than those of NT and CA plants, respectively (Fig. 5B). Furthermore, significant differences in root growth were observed among the three lines when they were treated with $100 \mathrm{mM} \mathrm{NaCl}$. The root dry weights of the NT, CA, and CAD plants treated with $100 \mathrm{mM} \mathrm{NaCl}$ were reduced by $75.0,67.8$ and $56.3 \%$, respectively, compared to their non- $\mathrm{NaCl}$ treated controls. The root dry weights of the CAD plants treated with $100 \mathrm{mM} \mathrm{NaCl}$ were found to be 2-fold and 1.5-fold higher than the weights of the NT and CA plants, respectively.

\section{Discussion}

In a previous study, we found that in CA tobacco plants expressing chloroplast SOD and APX, there was a synergistic effect of expression of the two enzymes with regard to protection against oxidative stresses (Kwon et al. 2002). It appears that the simultaneous scavenging by $\mathrm{CuZnSOD}$ of superoxide anion radicals and $\mathrm{H}_{2} \mathrm{O}_{2}$, which can deactivate CuZnSOD and APX, is important for the maintenance of plant productivity under harsh conditions. Exogenous ascorbate supplementation of NT and CA plants resulted in a decrease in the toxicity of MV (Kim et al. 2005). In CA plants, increased APX activity was found to be more relevant to the protection of plants against oxidative stress than increased SOD activity (Kwon et al. 2002). It has also been shown that chloroplast APX is the primary target of MVinduced oxidative stress (Mano et al. 2001). These results indicate that plants with larger ascorbate pools, accumulated by either ascorbate recycling or exogenous ascorbate supplementation, are able to maintain APX activity even under conditions of oxidative stress. Tobacco plants that overexpressed chloroplast-targeted DHAR, which catalyzes the reduction of DHA to AsA, also showed enhanced tolerance to oxidative and salt-induced stresses (Kwon et al. 2003). In this regard, we could surmise that transgenic plants expressing three transgenes, such as those encoding $\mathrm{CuZnSOD}$, APX, and DHAR, in their chloroplasts might be efficiently protected against a variety of environmental stresses.

In this study, we successfully generated CAD transgenic tobacco plants by the introduction of the DHAR gene under the control of the CaMV 35S promoter into the chloroplasts of CA plants (Figs. 1 and 2). CAD plants showed elevated protection against MV-mediated oxidative stress and high salt stress, more so than CA plants expressing CuZnSOD and APX (Figs. 4 and 5). As expected, CA plants showed an intermediate degree of stress tolerance relative to NT plants and CAD plants. The increased amount of AsA detected in the CAD transgenic plants was substantial with regard to its protective effect against oxidative stresses induced by MVor salt-treatment. Transgenic tobacco plants expressing the gene for wheat DHAR (Chen and Gallie 2004) contained larger quantities of AsA, and showed increased protection against ozone toxicity, although these plants also showed lower APX, SOD, and catalase activity than did NT plants (Chen and Gallie 2005). However, in addition to the increased quantities of AsA, the CAD plants in this study exhibited more profound SOD and APX activity than did CA plants.

It is known that only some of the total cellular ascorbate and glutathione content is localized in chloroplasts (Foyer 1997). In CAD plants, it seems likely that a large portion of AsA was located in the chloroplasts, because DHAR is targeted to chloroplasts. Also, in transgenic plants expressing $\mathrm{CuZnSOD}$ or APX, these proteins co-purified with chloroplast fractions (Sen Gupta 1993; Allen et al. 1997). It is likely that the DHAR protein in CAD plants was correctly targeted to the chloroplast, because the transit peptide sequence was the same as that of the chimeric APX construct. Thus, the higher redox state of ascorbate in the chloroplasts of CAD plants likely provided more tolerance against MV-mediated oxidative stress. Chen and Gallie reported the diurnal regulation of ascorbate redox state and $\mathrm{H}_{2} \mathrm{O}_{2}$ concentration in tobacco plants (Chen and Gallie 2004). In addition, it is known that the redox state of ascorbate is inconsistent in leaves at different developmental stages (Chen et al. 2003). In a previous report by our group (Kwon et al. 2003), we showed that the ratio of AsA:DHA in NT plants was 0.21. This difference in redox status between the current and previous study is most likely due to sampling time and slight differences in leaf development stages.

ROS, and hydrogen peroxide in particular, operate as critical signals for plant adaptation to both biotic and abiotic stresses (Mittler 2002; Mittler et al. 2004). Cellular ROS levels must remain under tight control in order for signaling during stress conditions to occur efficiently and accurately. A strong constitutive promoter, such as the CaMV 35S promoter, is typically used for the expression of foreign genes in plants. However, more precise regulation of expression using an inducible promoter, especially a stress-inducible promoter, often proves more useful for the development of stress-tolerant plants, or the production of proteins exerting deleterious effects on plant growth (Yoshida and Shinmyo 2000). We recently developed an oxidative stress-inducible POD promoter (SWPA2 promoter) from the sweet potato plant (Kim et al. 2003). Analysis of the SWPA2 promoter in transgenic tobacco plants indicated that it also might prove useful for the development of a plant exhibiting enhanced tolerance against environmental stresses. Transgenic 
potatoes (Tang et al. 2006) and sweet potatoes (Lim et al. 2004), expressing chloroplast CuZnSOD and APX under the control of the SWPA2 promoter were successfully developed and evaluated in terms of multiple stresses. These transgenic potato and sweet potato plants showed enhanced tolerance to a variety of stresses, including MV-mediated oxidative stress and extreme temperature. We are now attempting to introduce the gene encoding DHAR under the control of the SWPA2 promoter into transgenic potato plants that express chloroplast $\mathrm{CuZnSOD}$ and APX, using a gene-stacking approach.

In summary, we have developed transgenic tobacco plants designed for enhanced tolerance to oxidative stress that express chloroplast CuZnSOD, APX, and DHAR under the control of the CaMV $35 \mathrm{~S}$ promoter. Our results clearly indicate that the rational manipulation of the antioxidant mechanisms in chloroplasts by the coexpression of three antioxidant enzymes will prove important with regard to the protection of plant cells against multiple environmental stresses. Furthermore, we anticipate that our results will also prove applicable to the development of transgenic plants possessing enhanced tolerance to multiple environmental stresses.

Acknowledgements This study was supported by grants from the International Collaboration Project, Ministry of Science and Technology (MOST), Korea, from the BioGreen21 Program, Rural Development Administration (RDA), Korea, and from the KOSEF/MOST to the Environmental Biotechnology National Core Research Center, Korea.

\section{References}

Ahn YO, Kwon SY, Lee HS, Park IH, Kwak SS (1999) Biosynthesis and metabolism of vitamin C in suspension cultures of Scutellaria baicalensis. J Biochem Mol Biol 32:451-455

Allen RD, Webb RP, Schake SA (1997) Use of transgenic plants to study antioxidant defenses. Free Radic Biol Med 23:473-479

Asada K (1999) The water-water cycle in chloroplasts: scavenging of active oxygens and dissipation of excess photons. Annu Rev Plant Physiol Plant Mol Biol 50:601-639

Beauchamp C, Fridovich I (1971) Superoxide dismutase: improved assays and an assay applicable to acrylamide gels. Anal Biochem 44:276-287

Chen Z, Gallie DR (2004) The ascorbic acid redox state controls guard cell signaling and stomatal movement. Plant Cell 16:11431162

Chen Z, Gallie DR (2005) Increasing tolerance to ozone by elevating foliar ascorbic acid confers greater protection against ozone than increasing avoidance. Plant Physiol 138:1673-1689

Chen Z, Young TE, Ling J, Chang SC, Gallie DR (2003) Increasing vitamin $C$ content of plants through enhanced ascorbate recycling. Proc Natl Acad Sci USA 100:3525-3530

Foyer CH (1997) Oxygen metabolism and electron transport in photosynthesis. In: Scandalios JG (ed) Oxidative stress and the molecular biology of antioxidant defenses. Cold Spring Harbor Monograph Series 34, Cold Spring Harbor Laboratory Press, New York, USA, pp 587-621
Foyer CH, Lelandais M, Kunert KJ (1994) Photooxidative stress in plants. Physiol Plant 92:696-717

Graham WD, Annette D (1992) Determination of ascorbic and dehydroascorbic acid in potatoes (Solanum tuberosum) and strawberries using ion exclusion chromatography. J Chromatogr A 594:187-194

Griffith OW (1980) Determination of glutathione and glutathione disulfide using glutathione reductase and 2-vinylpyridine. Anal Biochem 106:207-212

Kim SH, Hamada T (2005) Rapid and reliable method of extracting DNA and RNA from sweetpotato, Ipomoea batatas (L.). Lam Biotech Lett 27:1841-1845

Kim JS, Lee BH, Kwon SY, Kim YH, Kim SH, Cho KY (2005) Antioxidative responses of transgenic tobacco plants expressing both superoxide dismutase and ascorbate peroxidase in chloroplasts to several herbicides. Kor J Plant Biotechnol 32:97-103

Kim KY, Kwon SY, Lee HS, Hur Y, Bang JW, Kwak SS (2003) A novel oxidative stress-inducible peroxidase promoter from sweet potato: molecular cloning and characterization in transgenic tobacco plants and cultured cells. Plant Mol Biol 51:831838

Kwon SY, Ahn YO, Lee HS, Kwak SS (2001) Biochemical characterization of transgenic tobacco plants expressing a human dehydroascorbate reductase gene. J Biochem Mol Biol 34:316321

Kwon SY, Choi SM, Ahn YO, Lee HS, Lee HB, Park YM, Kwak SS (2003) Enhanced stress-tolerance of transgenic tobacco plants expressing a human DHAR gene. J Plant Physiol 160:347353

Kwon SY, Jeong YJ, Lee HS, Kim JS, Cho KY, Allen RD, Kwak SS (2002) Enhanced tolerances of transgenic tobacco plants expressing both superoxide dismutase and ascorbate peroxidase in chloroplasts against methyl viologen-mediated oxidative stress. Plant Cell Environ 25:873-882

Lim S, Lee HS, Kwon SY, Kwak SS (2004) Development of transgenic sweetpotato plants with enhanced tolerance to environmental stress. In: Proceedings of the international workshop on production, utilization and development of sweetpotato, Mokpo Experiment Station, NICS/RDA, Korea, 6-10 September

Mano J, Ohno C, Domae Y, Asada K (2001) Chloroplastic ascorbate peroxidase is the primary target of methylviologen-induced photooxidative stress in spinach leaves: its relevance to monodehydroascorbate radical detected with in vivo ESR. Biochim Biophys Acta 1504:275-287

McKersie BD, Chen Y, De Beus M, Bowley SR, Bowler C (1993) Superoxide dismutase enhances tolerance of freezing stress in transgenic alfalfa (Medicago sativa L.). Plant Physiol 103:1155-1163

McKersie BD, Murnaghan J, Jones KS, Bowley SR (2000) Ironsuperoxide dismutase expression in transgenic alfalfa increases winter survival without a detectable increase in photosynthetic oxidative stress tolerance. Plant Physiol 122:1427-1437

Mittler R (2002) Oxidative stress, antioxidants and stress tolerance. Trends Plant Sci 7:405-410

Mittler R, Zilinskas BA (1994) Regulation of pea cytosolic ascorbate peroxidase and other antioxidant enzymes during the progression of drought stress and following recovery from drought. Plant $\mathrm{J}$ 5:397-405

Mittler R, Vanderauwera S, Gollery M, van Breusegem F (2004) Reactive oxygen gene network of plants. Trends Plant Sci 9:490-498

Murashige T, Skoog F (1962) A revised medium for rapid growth and bioassay with tobacco tissue cultures. Physiol Plant 15:473497

Nakano Y, Asada K (1981) Hydrogen peroxide is scavenged by ascorbate specific peroxidase in spinach chloroplasts. Plant Cell Physiol 22:867-880 
Noctor G, Foyer CH (1998) Ascorbate and glutathione: keeping active oxygen under control. Annu Rev Plant Physiol Plant Mol Biol 49:249-279

Payton P, Allen RD, Trolinder N, Holaday AS (1997) Over-expression of chloroplast-targeted $\mathrm{Mn}$ superoxide dismutase in cotton (Gossypium hirsutum L., cv. Coker 312) does not alter the reduction of photosynthesis after short exposures to low temperature and high light intensity. Photosynth Res 52:233-244

Sen Gupta A, Heinen JL, Holaday AS, Burke JJ, Allen RD (1993) Increased resistance in transgenic plants that overexpress chloroplastic $\mathrm{Cu} / \mathrm{Zn}$ superoxide dismutase. Proc Natl Acad Sci USA 90:1629-1633
Tang L, Kwon SY, Kim SH, Kim JS, Choi JS, Cho KY, Sung CK, Kwak SS, Lee HS (2006) Enhanced tolerance of transgenic potato plants expressing both superoxide dismutase and ascorbate peroxidase in chloroplasts against oxidative stress and high temperature. Plant Cell Rep 25:1380-1386

Yoshida K, Shinmyo A (2000) Transgene expression systems in plant, a natural bioreactor. J Biosci Bioeng 90:353-362

Yun BW, Huh GH, Lee HS, Kwon SY, Jo JK, Kim JS, Cho KY, Kwak SS (2000) Differential resistance to methyl viologen in transgenic tobacco plants that express sweet potato peroxidase. J Plant Physiol 156:504-509 